\title{
Research
}

\section{Eliciting the Implicit Knowledge and Perceptions of On-Ground Conservation Managers of the Macquarie Marshes}

\author{
Ioan Fazey ${ }^{1}$, Katrina Proust ${ }^{2}$, Barry Newell ${ }^{3}$, Bill Johnson ${ }^{4}$, and John A. Fazey ${ }^{5}$
}

\begin{abstract}
Knowledge that has been developed through extensive experience of receiving and responding to ecological feedback is particularly valuable for informing and guiding environmental management. This paper captures the implicit understanding of seven experienced on-ground conservation managers about the conservation issues affecting the Ramsar listed Macquarie Marshes in New South Wales, Australia. Multiple interviews, a workshop, and meetings were used to elicit the manager's knowledge. The managers suggest that the Macquarie Marshes are seriously threatened by a lack of water, and immediate steps need to be taken to achieve more effective water delivery. Their knowledge and perceptions of the wider societal impediments to achieving more effective water delivery have also led the managers to suggest that there may be system feedbacks that are reinforcing the tendency for water agencies to favor the short-term interests of the irrigation industry. Although the managers clearly have certain personal interests that influence their understanding and perceptions, much of their knowledge also appears to have been heavily influenced by their ecological understanding of the wetland's dynamics. This paper highlights that although all stakeholders clearly need to be involved in making decisions about conservation and how resources should be used, such decisions should not be confused with the need for consulting people with the appropriate ecological expertise to help determine the degree to which an ecological system is threatened, the likely ecological causes of the threats, and actions that may be needed to restore and maintain a functional ecosystem.
\end{abstract}

Key Words: conservation management; water resources; wetland; experience; traditional ecological knowledge; tacit knowledge

\section{INTRODUCTION}

There is increasing recognition of the importance of expert and experiential knowledge for informing and guiding environmentally related decisions (e. g., Woodwell 1989, Huntington 2000, Boiral 2002, Millenium Ecosystem Assessment 2005). In particular, there is an extensive body of literature that highlights the value of ecological knowledge of individuals and societies that have been embedded in their ecosystems and that have, on a regular basis and over long periods, received and responded to ecological feedback (e.g., Berkes et al. 2000, Pierotti and Wildcat 2000, Whiteman and Cooper 2000, Olsson and Folke 2001). Such individuals often exhibit the hallmarks of "adaptive experts" who have acquired extensive knowledge through their experiences, which affects what they notice and how they organize, represent, and interpret information (Bransford et al. 2000), and who learn and respond flexibly to unanticipated events in dynamically complex social-ecological systems (Fazey et al. 2005). This often allows them to recognize emergent properties of the system and make good predictions even though they might not always be able to explain precisely how they do it (Fazey et al. 2005).

Expert and experiential knowledge can broadly be separated into: explicit knowledge that has been articulated, implicit knowledge that can be articulated but has not, and tacit knowledge that cannot be articulated. Implicit experiential knowledge can sometimes be elicited quantitatively and integrated with similar forms of information (e. g., Calheiros et al. 2000, Kuhnert et al. 2005, Martin 
et al. 2005). However, implicit experiential knowledge is often difficult or impossible to elicit quantitatively because (1) it cannot easily be reduced to isolated facts or propositions (Bransford et al. 2000, Boiral 2002); (2) making it explicit means that it loses its connection with an individual's deep tacit knowledge (Polanyi 1958); and (3) it loses its connection with the context in which it is usually applied (Barab and Plucker 2002). Researchers have, therefore, often turned to qualitative techniques which have greater capacity to capture a person's holistic implicit knowledge (e. g., Lykke 2000, Olsson and Folke 2001, Robertson and McGee 2003).

This paper uses qualitative techniques to elicit the experiential knowledge of a group of seven experienced on-ground managers, referred to herein as the "managers," about the conservation of the Macquarie Marshes, referred to herein as the "Marshes," in southeastern Australia. The group was chosen because of their extensive experience of living and working in the Marshes and their active involvement in water management and policy development. It was expected that they would have indepth ecological knowledge of the degree to which the wetland was threatened, the causes of any potential biophysical threats, and knowledge about actions that may be required to alleviate the threats. This paper first articulates the managers' ecological and immediate societal knowledge, then clarifies their perceptions and understanding of the complex issues surrounding the conservation of the Marshes. In the discussion the difficulties of eliciting the knowledge, the nature and validity of the managers' understanding and the implications of the managers' knowledge are considered.

Although this paper aimed to elicit the understanding of a specific and experienced group of people, it is important to highlight that there are many stakeholders in the Macquarie Valley that have significantly different views of water resource issues to the on-ground managers. Nevertheless, it is hoped that the rigorous methods applied in this study to elicit the knowledge and perceptions of one group may form the basis of future work that captures the understanding and opinions of other groups, and that the sharing of perspectives will be promoted.

\section{APPROACH}

\section{Study area: The Macquarie Marshes}

The Macquarie Marshes are a large, complex, and ephemeral wetland situated in the lower third of the Macquarie River catchment in the central-west of New South Wales, Australia (Fig. 1). The Marshes cover around 220,000 ha (Brereton et al. 2000). Within this area, 21,654 ha is managed as a nature reserve by the Department of Environment and Conservation (DEC). However, the organization recognizes that in order to do this, the Marshes need to be managed as a single ecological unit. Although the organization has relatively little control over water resources, per se, it does have an influence on the development of policy through acting on behalf of the conservation interests of riverine systems and their dependent ecosystems. It also plays a role in decisions of how to use the water that is allocated to the environment.

The reserve is in three main blocks: the Northern and Southern Marshes, and the Ninia property. The Marshes are important ecologically with both the reserve and a private property being listed under the Ramsar Convention. The wetland is best known for its extensive reedbeds, river redgum forests, and is arguably Australia's most important breeding site for colonial nesting waterbirds (Kingsford and Auld 2003). The Marshes are also important for the economy of the local community, which is reliant on flooding to provide vegetation growth for cattle grazing (Brock 1996).

Water flows through the Marshes are highly variable, with the flora and fauna dependent on flooding events. However, the natural flow regime has been significantly altered since the completion of Burrendong Dam in 1966 (Kingsford and Thomas 1995, Kingsford and Johnson 1998). This dam is located $250 \mathrm{~km}$ upstream of the Marshes. Currently, there are seven significant dams in the Macquarie River catchment that regulate flows to support urban towns and agricultural enterprises (Wolfgang 2000). There is also considerable conflict between stakeholder groups due to competing interests and the over-allocation of water resources (see Smith 1998). This conflict is particularly pronounced during discussions of the degree to which the Marshes are threatened, the ecological causes of these threats, how best to manage the Marshes, and in discussions about water reform. The situation of the Marshes is just one of 
Fig. 1. Location map of the Macquarie Marshes.

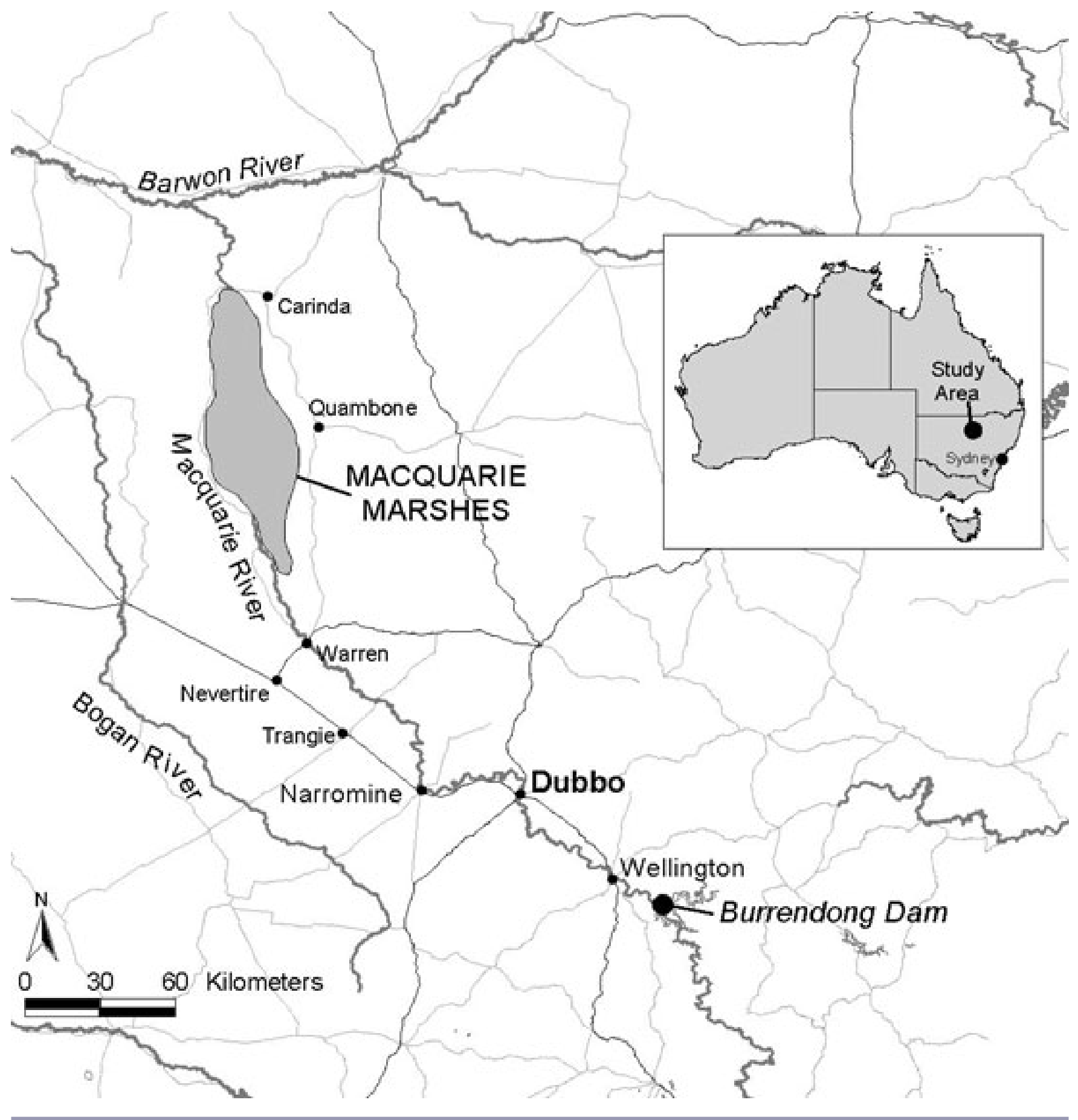


many examples of conflict between irrigated agriculture and wildlife conservation, which has reached a critical point on a global scale (Lemly et al. 2000).

\section{Participants}

Seven on-ground conservation managers participated in this study. The participants were all either staff of the DEC or members of the Macquarie Marshes Management Committee, an organization of private landholders working toward the sustainable management of the Marshes (Jones 2003). By "onground conservation managers," we mean people who are, or have been, based primarily at the Marshes, who have been regularly involved in providing ecological advice, and have regularly been representing the conservation interests of the Marshes in various local and regional meetings. All of the managers were also involved in managing some aspect of the ecological system, e.g., reserve management and/or cattle grazing, and/or have been actively involved in the development of water sharing plans or making significant contributions to committees that decide how to use water allocated for environmental purposes.

Individual managers were chosen primarily because of their extensive knowledge of the historical and current conservation of the Marshes. They had a total of $140 \mathrm{yr}$ of involvement in the management of water on the Marshes, $234 \mathrm{yr}$ of experience with the Marshes generally, and 275 yr of exposure to or working on Australian wetland and riparian systems. Some of the managers have spent most of their lives on the Marshes and have learned from previous generations of landholders with similar amounts of expertise.

\section{Method}

The research was conducted between February and August 2004, when the first author was primarily based at the Coonabarabran Area Office of the DEC. The implicit knowledge of the participants was captured using multiple interviews and a workshop. A group meeting was also held where the final written results of the research were presented and discussed (see Appendix 1 for full details of the methods). To articulate the perceptions of the managers about the feedback processes inhibiting conservation action a conceptual model of the social, economic, and ecological system of the Marshes was developed using causal loop diagrams (CLDs). Figure 2 illustrates the labelling conventions for CLDs and how to interpret them (see Sterman 2000 for detail).

The expressed implicit knowledge of the managers is presented in four separate parts in the results: (1) their underlying, primarily ecological convictions about the wetland; (2) their perceptions of the impediments to achieving effective water delivery; (3) their suggestions of immediate action that is required to help reduce the rate of ecological change on the wetland; and (4) their perceptions of the feedback dynamics that may be contributing to the difficulties of conserving the Marshes.

Sections 1-3 are derived from data collected during the interviews and the workshop. Section 4 presents the conceptual model of the Marshes system, which the researchers developed on the basis of the managers' views and using additional supporting documents. Extensive feedback on all sections of the results and Appendix 3 have been sought from the participants to ensure that their knowledge has been presented accurately (see Appendix 1). The results presented in this paper have therefore not been altered since incorporating the comments from the last interaction with the managers. This includes the language used, the way the results have been written, and the use of information from documents to which the managers referred. These documents have been referred to in the results for completeness.

\section{RESULTS}

\section{Part 1: Underlying convictions about the Macquarie Marshes}

The underlying convictions of the managers are based on their direct experiential knowledge of the wetland, observations of changes to the complex and dynamic ecological system, and their familiarity with various publications, reports, and documents. The four main convictions are: (1) The Marshes are an extremely important part of Australia's natural and cultural heritage; (2) A functioning wetland ecosystem is vital to the local community; (3) The Marshes are undergoing major ecological change and are seriously threatened; and (4) The main cause of the threat to the wetland is lack of water. 
Fig. 2. Labelling conventions for causal links. The arrows indicate that a change in variable A causes a change in variable B. Each link is assigned a polarity. The polarity of the causal link between A and B is said to be positive when an increase/decrease in A causes B to increase/decrease above/below what it otherwise would have been. A causal link is negative when an increase/decrease in A causes B to decrease/ increase below/above what it otherwise would have been. A short line indicates that there is a delay between a change in $\mathrm{A}$ and the corresponding change in $\mathrm{B}$.
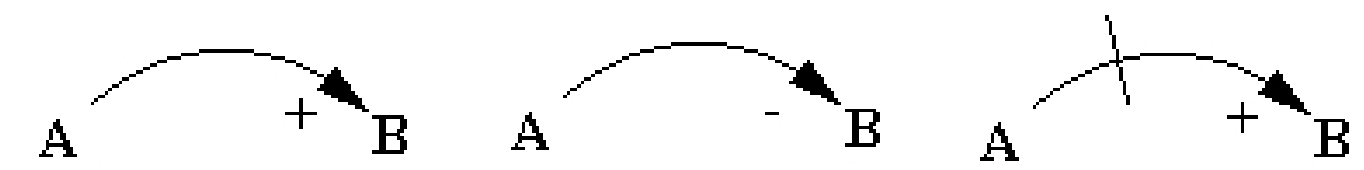

\section{The Marshes are important ecologically}

The Marshes are one of Australia's largest wetlands, and are arguably the most important site for the breeding of colonial waterbirds in Australia (Kingsford and Auld 2003). Some 220 species of bird, 15 fish, 14 snake, and 15 mammal species have been recorded in the nature reserve, and it is a prime example of the red gum-reed-water couch vegetation association (NPWS 1993). It includes the largest and most northerly extensive area of reeds (Phragmites australis) in southeastern Australia, has the largest area of river redgums (Eucalyptus camaldulensis) in New South Wales, and has one of the most southerly occurrences of coolibah $(E$. microtheca). Nine bird species are listed in the Japan-Australia and China-Australia migratory bird treaties, and 18 are listed as endangered (NPWS 1993).

The importance of the Marshes is formally recognized in a number of ways, including: The Ramsar Convention of 1971, the National Trust of Australia as a Landscape Conservation Area, the Australian Heritage Commission's Register of the National Estate, the directory of important wetlands of Australia, and the Japan-Australia and ChinaAustralia Migratory Bird Agreements (from Brock 1998).

The Marshes are important to the local community
Before European settlement, the Marshes were used extensively by the Wailwan aboriginal tribe. The site held special cultural and spiritual significance, and provided a regular source of food and water (Masman and Johnstone 2000). By the 1850s, most of the prime frontage of the Macquarie River was occupied by European settlers, and the pastoral industry had become well established.

The Marshes remain vitally important to the local community (Masman and Johnstone 2000, Jones 2003). Approximately one-third of the properties on the Marshes run only cattle, whereas two-thirds run a mix of cattle and sheep, with cropping occurring on half of the properties (Cunningham 1996). The community is dependent on an ecologically functional wetland, because cattle production is only possible in areas that are flooded more regularly. The Marshes are also a flow-through system, in which water passes through the wetland to service downstream users.

Recognition by the community of the importance of the wetland is exemplified by the good relationship between the Macquarie Marshes Management Committee and the DEC. Given its relatively remote location, the cooperation of landholders for the management of the nature reserve is essential. Landholders report trespassers and are often the first people present in the event of bushfire. They have also played a significant role in 
highlighting the plight of the wetland, and many individuals have contributed substantial amounts of their time in activities related to water resource management.

The Marshes are undergoing major ecological change and are seriously threatened

\section{Broad ecological and social changes}

Because of the complexity of the wetland system, some of the strongest evidence for major change on the Marshes comes from the observations of the managers. Over the past $30 \mathrm{yr}$, the managers have observed a general drying out of the Marshes. They point to clear indicators of change. These include the loss of large areas of ephemeral wetland vegetation, dying of river redgums, and the regular appearance of deep cracks in the substrate. For example, in what used to be one of the wetter areas of the North Marsh (P Block), the 1982 drought was the first time in living memory that people could ride from the stock yards and not come across water. According to the managers, landholders are now generally surprised when the area is wet, because it seems to be dry most of the time. The fire trail that was constructed out to the Bora Well in 1994 provides another example. Construction of this trail was not previously possible, and it still remains clear even though similar trails usually grow over within 2-3 yr.

The South Marsh has seen some of the greatest change. Here, large areas of wetland vegetation have disappeared to be replaced by weeds. For example, the reed-beds were burnt in 1992 as part of a fire-management program. The area did not recover, even though regrowth is usually expected one yr after a fire. It appears that the underlying root system had already died due to lack of water, and all that remained before the fire was surface vegetation. Overall, by the 1990 s, only $50 \%$ of the reed bed in the South Marsh remained compared to the situation before river regulation (Brander 1987). Now, less than $10 \%$ remains.

There are suggestions that unusual events are occurring in response to changes in water flow. In many areas, river redgums are stressed or dying due to lack of water. In other areas, in which ephemeral wetland vegetation is normally present, young trees are sprouting. This appears to be due to floods of smaller volume, which do not persist long enough to drown sprouting redgums. Assuming that the young trees obtain enough water to survive, they will shade out more ephemeral wetland vegetation, resulting in the development of more homogeneous vegetation structures. In addition, in some areas, the water table appears to have dropped, and because of the deepening of channels, it now takes an estimated three times the amount of water in the channel before overbank flow and flooding of the wetland can occur (Brereton 1994). Weeds such as Noogoora burr (Xanthium occidentale) and Lippia (Phyla nodiflora), which are normally kept under control by flooding are also becoming a problem and are outcompeting natural vegetation.

Social changes have also occurred in the local community, which appear to be related to changes in the capacity of the ecological system to sustain agricultural practices. The number of families supported on the Marshes has fallen from about 50 to 30 over the past $30 \mathrm{yr}$, and the size of properties has increased as landholders have bought land in an attempt to maintain a viable income. Although it is difficult to attribute such changes directly to a decline in the carrying capacity of the wetland, according to the managers, areas adjacent to the Marshes have not undergone such dramatic declines in population or seen a similar amalgamation of property.

\section{Waterbird breeding}

There is limited peer-reviewed literature on the management of the Marshes. Most of the existing published research concentrates on the breeding of colonial nesting waterbirds. This research clearly demonstrates a significant decrease in the frequency of breeding events and the size of bird colonies since river regulation (Kingsford and Auld 2003), and is supported by the observations of the managers. Bird breeding is usually triggered when annual flows exceed 200,000 ML. Flooding on the wetland also needs to be of a sufficient duration for breeding success (Kingsford and Johnson 1998, Kingsford and Auld 2003). When flows are between 200,000 and 500,000 ML, breeding colonies are usually less than 20,000 pairs (Kingsford and Johnson 1998). Estimates suggest that before river regulation, over 100,000 breeding pairs may have been involved in each breeding event. During the three large floods of the 1950s, colonies may have been much larger (Kingsford and Johnson 1998).

Between 1985 and 1995 there was a total of 124,000 nests of six heron and ibis species. This was 
estimated to be half of what would have occurred if no water had been diverted, and although it was estimated that a median of 4000 nests would have been constructed each year, only 200 nests/yr were observed (Kingsford and Johnson 1998). There have also been decreases in the number of bird breeding events. Although the managers suggest that at least one breeding event every two years is expected, there have been none in the past four yr. This was despite sufficient rainfall in the upper catchment in August 2003 to trigger a bird breeding event if the water had not been captured in the dam (Kingsford 2004).

\section{River redgums}

A recent study for the DEC of the health of river redgum trees at 22 sites in the Macquarie Marshes clearly indicated that trees that had received water in the past two yr had a similar health to these same trees that were assessed in 1994 (Woodlots and Wetlands Ltd. 2004). Trees that had not received flooding since 2000 had a $61 \%$ decline in canopy density as well as significant increases in dead branch frequency and epicormic growth. In some plots, over $30 \%$ of trees had died over the past decade. There was no evidence that the decline in tree health was due to factors other than to a lack of water. In order to prevent further death of river redgums, it was recommended that the wetlands receive flooding as soon as possible, and preferably before the summer of 2004-2005. This did not occur due to lack of available water in the dam. Extrapolating from the study by Woodlots and Wetlands Ltd. (2004), the managers suggest that $75 \%$ of the estimated 20,000 ha of river redgum forest on the Marshes are showing signs of stress from lack of water. It is not known to what extent other tree species that grow in the peripheral areas of the Marshes are under stress, because many of these species are less reliant on frequent flooding, and the effect of a lack of water takes longer to become apparent.

\section{The Marshes are seriously threatened}

Overall, the managers believe that the Marshes are so seriously threatened that if no large floods occur within the next $5 \mathrm{yr}$, the South Marsh area of the nature reserve will be lost altogether, and that the majority of the North Marsh will have been lost or its ecological character significantly and irreversibly altered.
The main cause of the threat to the Marshes is lack of water

Over the past $40 \mathrm{yr}$, the managers have observed a significant decrease in the amount of water reaching the Marshes and point to a number of publications and reports that supports their observations. In general, water flows at the gauging station below the Marshes have decreased significantly for high and medium rainfall events, and the area flooded by large floods has contracted by at least $40-50 \%$ between 1944 and 1993 (Kingsford and Thomas 1995). Between 1944-1953, 51\% of all water passing through the city of Dubbo reached the wetland, but by 1984-1993 this had decreased to 21\% (Kingsford and Thomas 1995).

The volumes of water allocated to the environment have increased in subsequent water sharing plans, but the managers point out that it still falls very short of being able to maintain the ecological character of the Marshes. Although more recent changes on the Marshes have been exacerbated by the 2001current drought, the main cause of the lack of water is over-extraction upstream, which has reduced the capacity of the Marshes to withstand extreme natural events (Kingsford 2004). In the Macquarie Valley, $89 \%$ of the water that is extracted is used for irrigation, with the dominant irrigation enterprise being cotton production (Wolfgang 2000, DLWC 2002).

There are many management issues for the Marshes, including the control of feral animals, weeds, erosion, fire, and salinity (NPWS 1993). However, most of these are closely related to issues of water delivery. For example, flooding is one of the most efficient ways of controlling or inhibiting the growth of weeds, and erosion is also primarily caused by more continuous low flows of water through the channels. It has been suggested that agricultural land-use practices that are less reliant on irrigation both within and upstream of the Marshes, e.g., grazing, have considerable environmental impact (e.g., Kidson et al. 2000). However, the managers point out that areas of the nature reserve that have not been grazed since 1989 are exhibiting as much, and sometimes more change, than in areas outside the reserve. Thus, although there may be a number of management issues for the Marshes, effective long-term conservation of the wetland can be achieved only by first solving the issues of effective water delivery. 
Table 1. The main requirements for achieving an appropriate flow regime for the Marshes. Only some of the examples are presented.

\section{Main requirement Examples of requirement}

Delivery of a sufficient overall volume of water

\begin{abstract}
A minimum of 200, $000 \mathrm{ML}$ of water are required to trigger a breeding event of colonial nesting waterbirds (Kingsford and Johnson 1998). Breeding events are occurring less frequently than before river regulation due to lack of sufficient volumes of water (Kingsford and Johnson 1998).
\end{abstract}

To achieve floods that are large enough to cover vegetation that is dependent on inundation, but at less regular intervals than wetland vegetation at the wetland core, at least 400,000 ML is required over a period of 0-300 d (Kidson and Raisin 2000).

Delivery of water at appropriate rates of flow

Flows are required at sufficient rates to prevent erosion and to generate widespread flooding. In some areas erosion is occurring in some of the wetland channels and it now takes three times the amount of water in the channels to achieve overbank flow and flooding of the surrounding wetlands (Brereton 1994).

To ensure floods persist for appropriate periods of time

Delivery of water at appropriate times within years

\section{be}

Effective breeding of colonial nesting birds requires flooding of sufficient duration to ensure birds do not abandon their nests (Magrath 1991, Kingsford and Auld 2003).

The main breeding season for birds was thought to be between August and November before the 2000).

Delivery of water at appropriate times between years

\section{Why the requirement is not being met}

The volume of water allocated to maintaining an ecologically functioning environment is insufficient for bird breeding. Water allocated to the environment is $160,000 \mathrm{ML}$ in a year when there is sufficient water in the dam for a $100 \%$ allocation (DLWC 2002).

Large floods have significantly decreased in the Marshes since construction of the dam.

Estimates from theoretical modeling suggest that they have decreased by at least $25 \%$ (Brereton et al. 1996), whereas mangers suggest that the decrease is much greater. Large floods are currently only possible when the dam spills.

Continuous low flows of water to service irrigation and stock contributes to the erosion (Brereton 1994), and limited size of the dam valves and restrictions on the floodplain upstream of the Marshes prevent high rates of flow.

Lack of sufficient overall volumes of water mean that it is difficult to achieve a tail on the flood that is long enough to ensure young birds can fledge and can build strength.

The breeding season for colonial birds in the Marshes is now two to three months later, due to the release of water from storage in spring and summer to satisfy irrigation and stock requirements (Kingsford and Auld 2003).

River regulation aims to reduce variability.
The Marshes are adapted to natural variation in flooding between years, but this variation has been significantly altered. For example, 2001-2004 were dry years with no bird breeding events, but rain that fell in August 2003 would have been sufficient to generate a breeding event if it had not been captured by the dam (Kingsford 2004). 
Table 2. Impediments to achieving effective delivery of water to the Marshes.

\section{Impediment}

\begin{tabular}{ll}
\hline Biophysical & $\begin{array}{l}\text { Insufficient water } \\
\text { allocated to the } \\
\text { environment in water } \\
\text { sharing plans to } \\
\text { sustain the wetland }\end{array}$
\end{tabular}

Natural tributary flows, used as additional irrigation resources, no longer reach the Marshes

Flow of water for irrigation occurs at a different time of year than rainfall periods

Physical impediments on the floodplain

Size of release valves in the dam

Translucent flows

Political Lack of will/ability to make significant changes

Social Threat of litigation

\section{Explanation}

The volumes of water allocated to environmental flows are insufficient to maintain the ecological character of the Marshes (see Table 1 and underlying convictions)

When rain enters the Macquarie River below the dam through tributaries, water release from the dam intended to service irrigation is reduced, and the tributary flows are used instead. However, tributary flows, which account for approximately $10 \%$ of the total amount of catchment water that would naturally have entered the Marshes, could significantly contribute to achieving: (1) larger floods and (2) more natural variability.

Water is released from the dam for irrigation and stock watering during the summer months and may, therefore, enter the Marshes during this period. Rainfall in the upper catchment usually occurs during winter.

Urban and agricultural development on the floodplain upstream of the Marshes creates a bottleneck, making it difficult for large volumes of water, which are necessary for widespread flooding, to reach the wetlands.

The small valves prevent the release of large volumes of water, which reduces the capacity for flooding the wetland. Large floods on the wetland are only possible when the dam spills, which is a rare event.

Translucent flows aim to mimic a natural flow of water out of the dam by releasing water when it rains in the upper catchment. However, because of the size of release valves, only low volumes can be achieved. This process has failed to reproduce natural conditions and has contributed to channel erosion.

Many politicians at the state and federal level appear unwilling or unable to act to achieve changes that will help to achieve effective water delivery. This is partly due to (1) the lack of public awareness about the ecological state and importance of the Marshes and, hence, lack of public support for politicians to take difficult decisions; (2) pressure from an irrigation industry that has substantial economic leverage and has considerable lobbying power; and (3) the perception that the region has "safe" electoral seats, which reduces politicians' willingness to make policy changes.

Previously, Macquarie River Food and Fibre, representing individuals who have developed agricultural enterprises on the floodplain, have threatened legal action against water agencies if access to their properties is restricted by large releases of water from the dam. This (1) creates pressure on the water agencies to conform to the requests of irrigators, and (2) decreases the possibility of achieving medium to large floods on the Marshes. 
Public perception that the Marshes are healthy

Public perception that the Marshes receives a lot of water
There is a general perception in the region that the Marshes are either healthy, or are within a natural drought period. This means that people are (1) less concerned about the Marshes, and (2) are less willing to support political actions.

Water released from Burrendong Dam to service irrigation, stock, and domestic use upstream of the Marshes generates a perception in the region that the Marshes receives a lot of water. This is despite the problem that the volume of water is significantly less than that which the Marshes would have received historically, and that much of the continuous low volume flows that reach the Marshes goes round the wetland via the Northern Bypass Channel to service downstream users.

Lack of general public interest in the conservation of the Marshes

Institutional Lack of will/ability to enforce floodplain restrictions

Policies preventing dam spills

Lack of neutrality of government water agencies
There is a lack of public knowledge about the Marshes. Despite the size of the wetland, many people who live in the region have never visited them.

It appears that the water agencies are incapable of enforcing floodplain regulations. This can be due to (1) lack of resources, or (2) inability to deal with the pressure from different stakeholders. For example, in recent meetings of the local floodplain management committee, for managing areas upstream of the Marshes, representatives of the Macquarie Marshes Management Committee and the National Parks and Wildlife Service (NPWS) have been barred by private landholders from conducting site visits to assess impacts of floodplain development. The water agencies, which have been allowed access, have resorted to a reassessment of the water flow models, at considerable cost, rather than enforcing previous decisions.

Water agencies appear to ensure that as much water as possible entering the dam can be retained for allocation to different stakeholders. This also includes maintaining "air space" to ensure that if it does rain, then no water is "wasted" through dam spills.

The managers provide numerous recent examples of policies and management by water agencies that favour the interests of the irrigation industry over environmental and other interests (see text).

\section{Part 2: Impediments to effective water delivery}

To the managers, "effective water delivery" means the establishment of an appropriate water flow regime that is able to maintain the ecological character of the Marshes. That is, a flow regime that does not impair or imbalance any of the processes or functions which maintain the products, attributes, and functions of the wetland (e.g., as described in O'Connell 2003). Given the degree of variability of natural water flows before river regulation, the managers recognize that determining an appropriate regime is extremely difficult. However, they suggest there are five main requirements for a flow regime to be considered appropriate, none of which are currently being fully met (Table 1 ). These requirements are similar to the main parameters used for assessing hydrologic alteration (Richter et al. 1996).

The managers believe there are a number of interacting physical, social, political, and institutional impediments to achieving effective water delivery (Table 2). They were particularly concerned about the lack of neutrality of the water agencies. The managers gave numerous examples of policies and management decisions that appeared to have been made in favor of irrigation over 
Fig. 3. Economic growth. The reinforcing causal loop $(\mathrm{R})$ illustrates some of the social factors contributing to, and arising from, a belief in the advantages of economic growth. As the tendency in the community to focus on the short-term economic returns from irrigation increases, it reduces the tendency to focus on long-term sustainability.

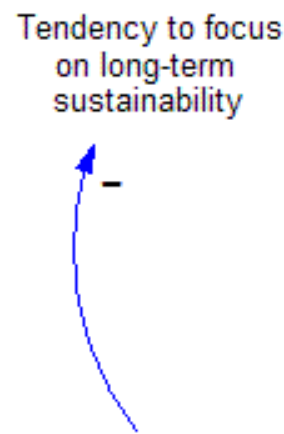

Tendency to focus on short-term economic returns<smiles>[13CH3]</smiles>

Desire for immediate high profit agricultural enterprise

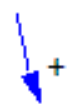

Commitment to irrigation-dependent enterprises by some communities
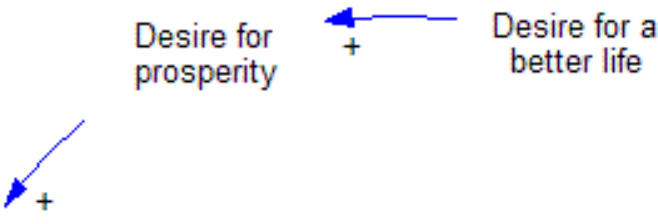

Belief in advantages of economic growth

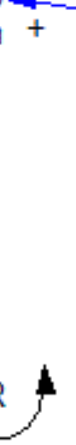

\section{Perception of community prosperity}

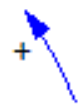

Contribution of irrigation to economic growth<smiles>C[14CH]I</smiles>

\section{Economic Growth}

Profits from irrigation

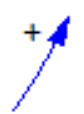

Production from irrigation

Size of irrigation

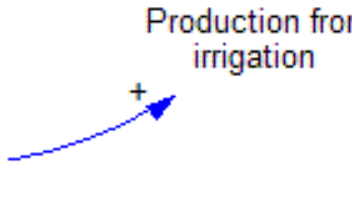

environmental or other concerns. The managers provide a number of examples that have occurred in the past four yr, since 2000, in which the water agencies have: (1) ignored the requests of the River Management Committee (RMC); (2) manipulated the rules of the water share plans against the wishes of the RMC; (3) regularly made it difficult to use the water allocated to maintaining environmental flows; and (4) undermined the decision-making process and reneged on promises to support environmental interests. The managers also point to the NSW Government 2000 Water Management Act, which clearly states that the extraction of water must not prejudice the protection of a water source 
Fig. 4. Conflict among water users. The reinforcing causal loop (R) illustrates some of the social factors that result from increased pressure on water resources. As conflict over water increases, the pressure on politicians to find solutions increases. This increases the tendency for politicians to search for quick solutions, resulting in increased pressure on water agencies to provide the same.

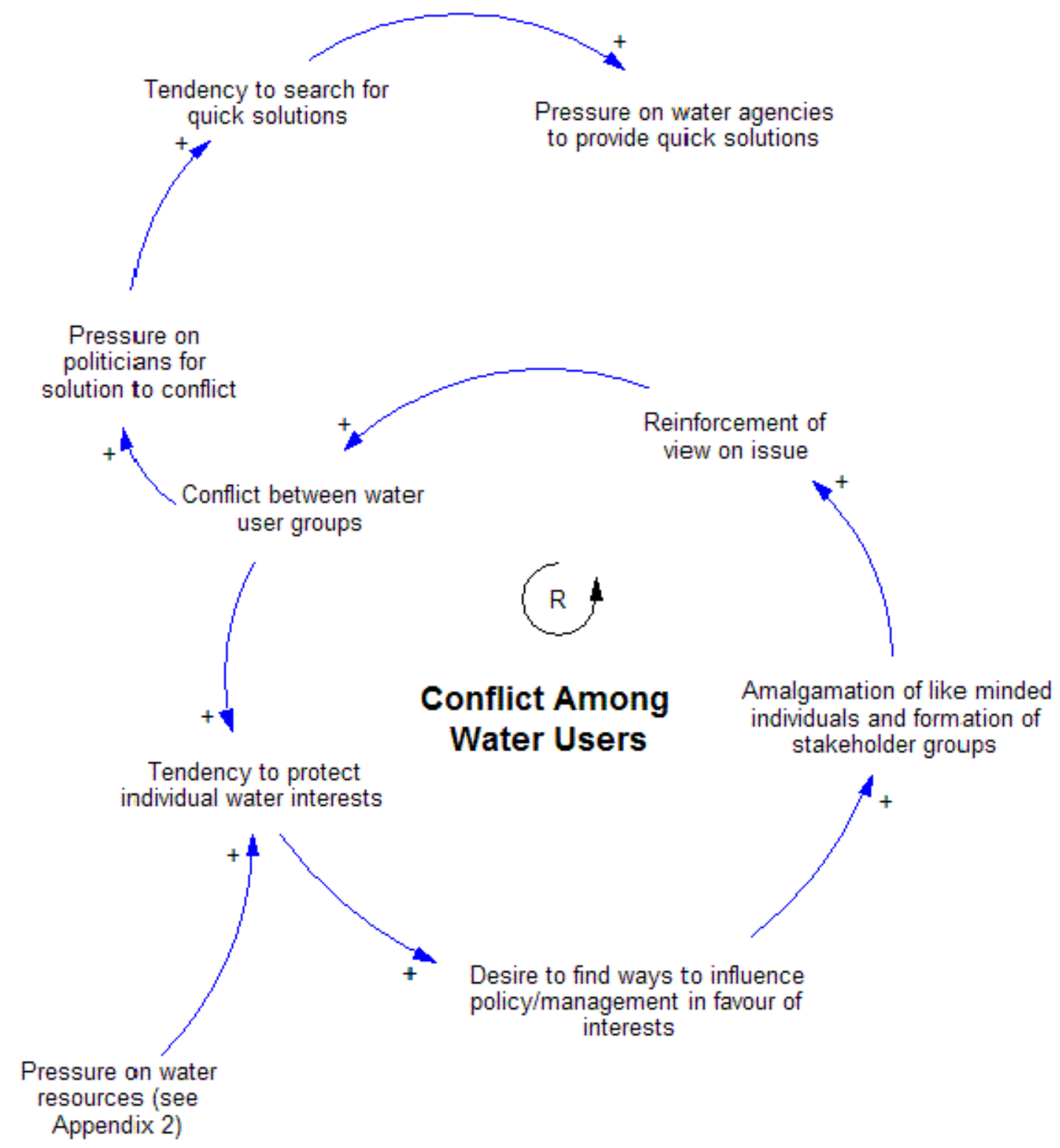


Fig. 5. World views of water agencies. The reinforcing causal loop (R) illustrates some of the effects of the traditional engineering view and the traditional resource-use view prevalent in water agencies. Combined with the lobbying power of the irrigation industry, the world views of the water agency increase the potential for policy and/or management to favor irrigation over other interests.

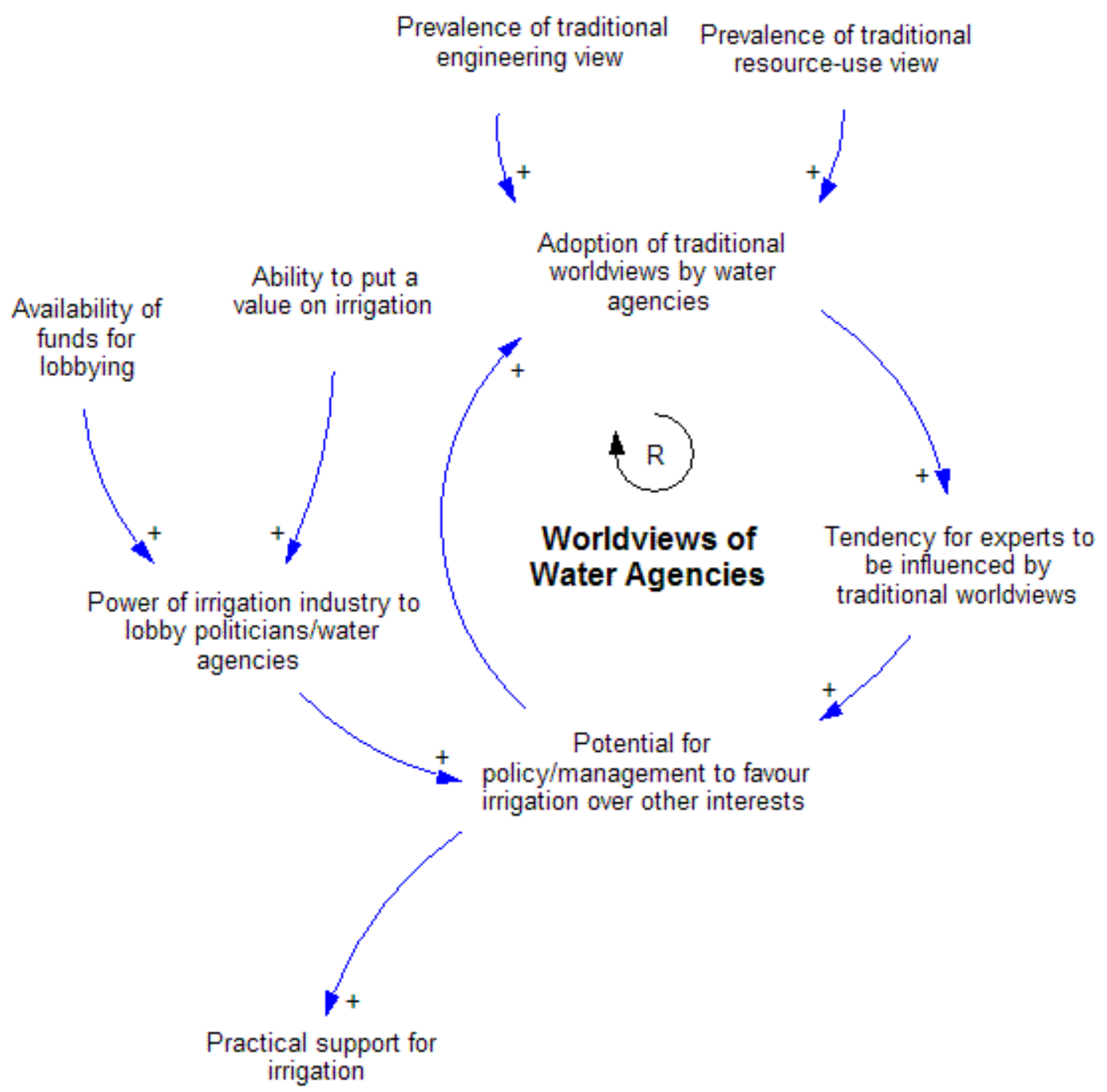

and its dependent ecosystems and basic landholder rights (NSW Government, Chapter 2, Part 1, Division 1). They believe that the act is not being followed.

The managers have had considerable difficulty communicating with the water agencies. They suggest that it often takes several months to obtain replies to letters, and it is difficult to obtain updates of accounts of the water allocated to maintaining environmental flows. In some cases, water allocated to the environment has not been forthcoming and, according to the managers, appears to have been used to service other interests. For example, in 2002, 
Fig. 6. Community, politics and rnvironment. The reinforcing causal loop (R1) illustrates the social effects that may result when the community takes an interest in the environment. The reinforcing causal loop (R2) illustrates the effects that this interest may produce in the political domain. As actions in favour of the environment increase, so does the capacity of the Macquarie River to withstand extreme events or threat from detrimental human activities.

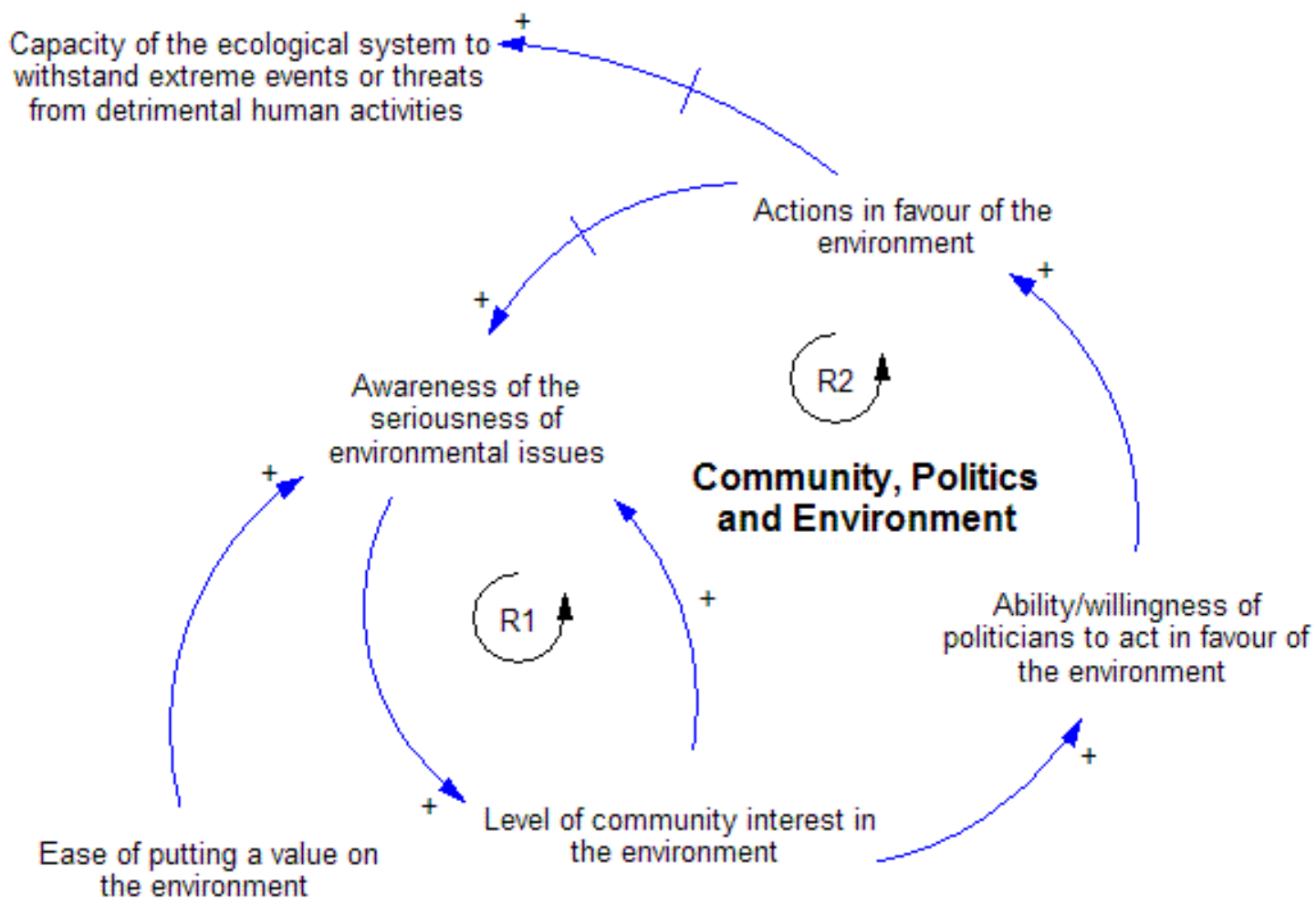

an informal committee set up to manage the environmental water that included some of the managers decided to release the total amount of water that was supposed to be available in the account (76,000 ML). However, the committee was informed that only 45,000 ML were available as the other 31,000 ML were accounted for in rainfall that had not fallen yet. The managers had to wait until the following year before they could access the remaining water that had been allocated to the environment. This resulted in two separate smaller floods over two years, contributing to considerable stress and death of wetland trees in areas that a single, larger flood would have covered.

The managers have an almost total lack of confidence in the willingness of the water agencies to service the broader environmental and community interests of the Macquarie Valley. They point out that this problem is not new, and they refer 
Fig. 7. The Marshes system. Key variables in the individual causal loop diagrams (CLDs) described in Figs. 3-6 collectively illustrate important connections between the subsystems. With this wider view of the system, additional feedback dynamics become visible. The loop labelled Economic Growth (R1) is linked to Pressure for Solutions (R3) via the power of the irrigation industry to lobby politicians or water agencies. The loop labelled Worldviews of Water Agencies (R2) is linked to Pressure for Solutions (R3) via the potential for policy/management to favour irrigation over other interests. The loop labelled Conflict among Water Users (R4) is linked to Pressure for Solutions (R3) via conflict between water user groups. These links form part of the positive feedback behavior driving the system. Increasing potential for policy and management to favor irrigation decreases actions in favor of the environment (R5), while a decreasing tendency to focus on long-term sustainability decreases awareness of the seriousness of environmental issues (R5). This ultimately leads to a decrease in the capacity of the Macquarie River to withstand extreme natural events or threats from detrimental human activities.

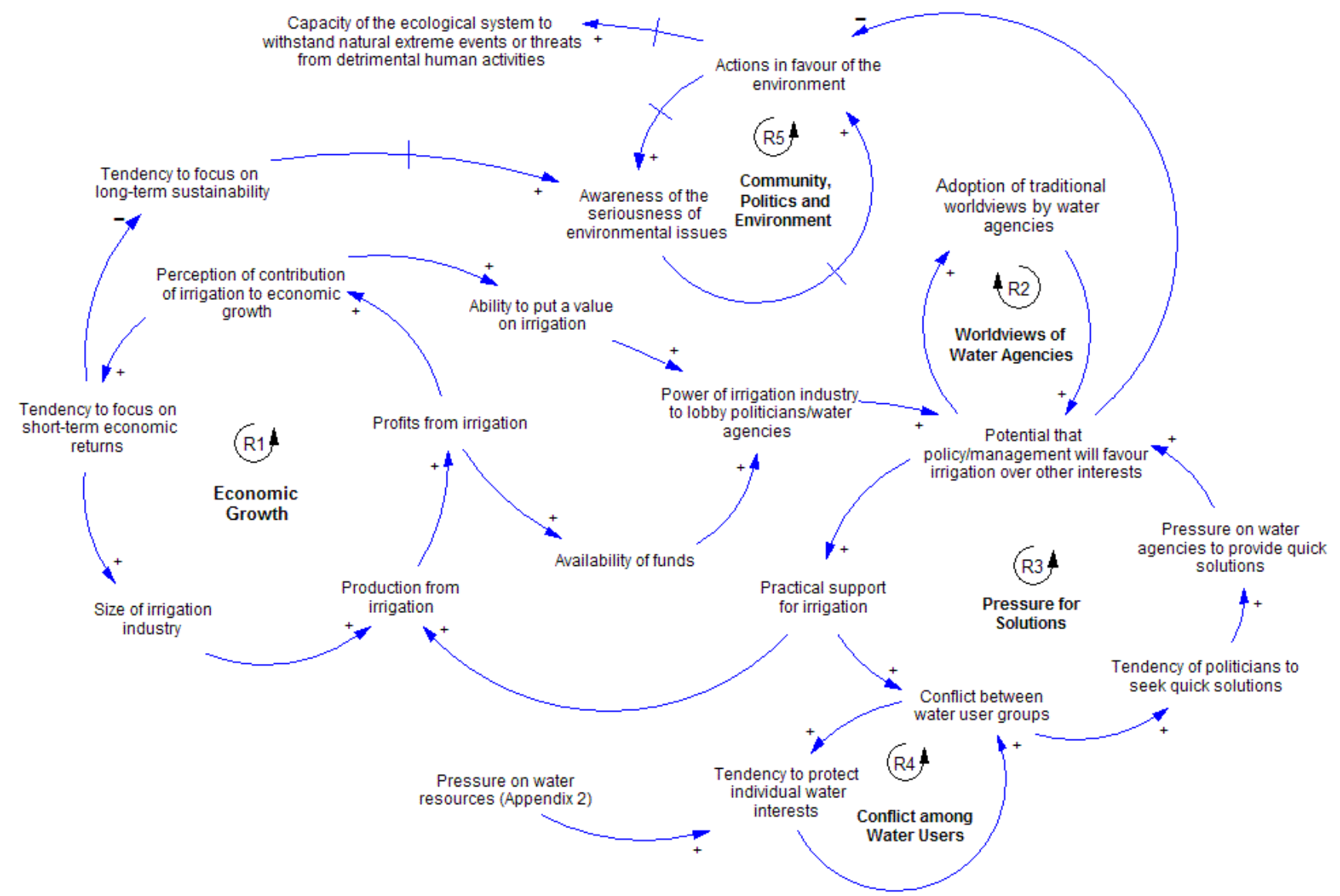

to the Water Administration Audit in 1986 in which the NSW parliament approved the abolition of the Water Resources Commission (WRC):

The audit found that the WRC was ineffective in management of the states' water resources, having difficulty in moving beyond its former role of rural supply authority. Broad water needs of the whole community, including the needs of the natural environment, were residual considerations to irrigation development and operations. 
It is likely that the extent of powers available to the WRC in development of the Water Management Plan for the Macquarie Marshes will radically change, as will the overall management philosophy. The new Department of Water will be required to address cultural, scientific, and aesthetic values as legitimate community needs in terms of water management (DEP 1987).

According to the managers, the culture of the water agencies is still focused on servicing the interests of the irrigation industry. Although there have been some positive changes, as far as the managers are concerned, these have not yet resulted in any significant visible outcomes for the Marshes, and only appear to be slowing the rate of ecological change rather than reversing the trend.

\section{Part 3: Suggestions for immediate action}

To achieve more effective water delivery, the managers suggest three important actions that could immediately help slow the rate of ecological change of the Marshes. First, it is suggested there should be an embargo on extracting water that enters the river below the dam, through tributaries, or water that is released from the dam during controlled spills. This would enable more extensive and natural variability of floods on the Marshes when rainfall in the catchment is high. Second, greater enforcement is required to ensure that volumes of water extracted from the river are not greater than that stipulated in the licences. Third, water licences need to be purchased to increase the volume of the water that is used to maintain environmental flows.

\section{Part 4: Managers' perceptions of why conservation of the Marshes has been, and continues to be ineffective}

This section presents a conceptual model of the Marshes system as perceived by the managers that provides tentative hypotheses of some of the feedback dynamics of the system that appear to be acting to reduce the likelihood of achieving effective conservation actions, i.e., actions that ensure the long-term maintenance of the ecological character of the Marshes. The reinforcing feedback loops are first explained individually and are then presented in an overall, integrated CLD of the Marshes system.

\section{Belief in economic growth}

Figure 3 illustrates the continual reinforcement of the Macquarie Valley community's belief in economic growth. Historically, the search for a better life drove early settlement. The individual's desire for prosperity continues in the Macquarie Valley today, with a prevailing belief that economic growth will satisfy this desire. A belief in economic growth tends to focus attention on short-term economic returns, leading to support for high-profit agricultural enterprises. In Australia, between the late 1960 s and late 1990 s, cotton production has increased twenty-fold, with the result that cotton is now Australia's fifth largest agricultural export, making Australia the world's fourth largest cotton exporter (Eslake 2002). A similar increase in cotton production has occurred in the Macquarie Valley since the construction of the dam. These developments have contributed to the community's perception that irrigation contributes to community prosperity. These perceptions then lead to increased levels of commitment to economic growth. The tendency to focus on short-term economic returns decreases the tendency to focus on long-term ecological sustainability.

\section{Conflict among water users}

Pressure on water resources (see Appendix 2 for details) inevitably leads to conflict between water user groups, as shown in Fig. 4. As the tendency to protect individual water interests increases, so does the amalgamation of like-minded people. This acts to reinforce the opinions of individuals, exacerbating any existing conflict among groups, and further increasing the tendency to protect individual water rights. Conflict among water user groups increases the pressure on politicians to find solutions, and because of the short terms of office, politicians are likely to try to find quick answers or short-term solutions that delay the need to make major changes. This also increases pressure on the water agencies to find quick or short-term solutions.

\section{World views of water agencies}

Figure 5 illustrates how the adoption of traditional engineering and resource-use world views influences the policy and management decisions of the water agencies. The water agencies were originally established to service the irrigation industry, and water-management decisions were primarily made by the same engineers who were 
charged with the construction of water-delivery schemes (Proust 2004). Although there has been much restructuring and numerous name changes to the New South Wales water agencies (Proust 2004), according to the managers of the Marshes, the prevailing world views and culture of successive water agencies continue to focus on servicing irrigation and controlling the natural variability and uncertainty of water flows. World views affect the unconscious perceptions of a group of people (Kalu 2001), and have both implicit and explicit influences on policy and management.

In addition, according to the managers, compared to many other stakeholder groups, the irrigation industry has significant lobbying power and access to water agencies and politicians. The power is derived from (1) the ease with which an economic argument can be made for supporting the industry because of the immediate economic returns gained from irrigation, and (2) the funds available for lobbying. Overall, the prevailing world views of the water agencies and the extensive lobbying power of the irrigation industry increases the likelihood that policy and management will favor irrigation.

\section{Community, politics, and environment}

Figure 6 illustrates some of the perceived relationships between political actions in favor of the environment, and community awareness. Increasing awareness increases the level of community interest in the environment, which also acts to increase the community's awareness of environmental problems (R1). Increasing community interest also increases the likelihood that politicians will act in favor of the environment (R2), which increases the capacity of the ecological system to withstand natural extreme events or threats from detrimental human activities.

\section{Linking current feedback loops and the managers' wider view}

Figure 7 represents the managers' wider view of the Marshes system showing the links between the variables in Figs. 4-7. In their view, strong feedback effects reinforce the potential that policy and/or management will favor irrigation, thereby reducing environmental awareness and action (R5). The likelihood that policy and management will favor irrigation is driven by: irrigation activities that provide lobbying power (R1); the traditional world view of the water agencies (R2); and the tendency for politicians to seek advice from the water agencies to solve conflict (R3 and R4). Decreased actions in favor of the environment, ultimately, lead to a decrease in the capacity of the ecological system to withstand natural extreme events or threats from detrimental human activities. This appeared to be the case in the Marshes in January 2005, when a fire, lit by lightning, burnt $90 \%$ of the main 2000 ha reed bed. This would not normally be a problem because reeds usually regrow very quickly, but it appears that because there was so little moisture in the soil, the root structure of the reed bed had also been burnt over large areas.

These perceptions suggest that additional major government intervention and shifts in the current views of the Macquarie Valley community to views that favor more sustainable economic activity will be necessary to secure the long-term conservation of the Marshes.

\section{DISCUSSION}

\section{Difficulties eliciting the implicit knowledge}

In this study, considerable effort was made to accurately elicit and communicate the implicit knowledge and perceptions of the managers. This included a component of participation, interviews, a workshop, and a group meeting (see Appendix 1). Importantly, many of the research steps allowed opportunities for the researcher to seek feedback and evaluate the accuracy of interpretations.

Considerable time and interaction was required to ensure not only that individuals' understandings were captured correctly, but that the understanding of the collective was being communicated appropriately. This meant that facilitative elements were necessary to integrate various data from different managers in a way that was acceptable to the other participants (see Fazey et al. 2005). This process was only possible because of the close working relationship and common outlook of the majority of the participants. However, even until the final research stage, the researchers' interpretations of this collective understanding were sometimes inaccurate, e.g., the primary researcher had greatly reduced the emphasis of the managers' experiences, which had led them to believe water agencies were not neutral. Therefore, considerable care and attention will always be required if a group's 
understanding is to be portrayed accurately. This is especially important in situations in which information is sensitive and when other groups are likely to have significantly different opinions.

It was also difficult, if not impossible, to separate the managers' knowledge from information in published reports and papers. Research results generally provide experiences that contribute to the development of an individual's understanding, and are important for helping break erroneous ways of thinking (Sutherland et al. 2004). Therefore, it is not surprising that the managers often referred to information that had already been made explicit. It was also deemed inappropriate to triangulate the knowledge of the managers with such explicit sources, because the documents had often already influenced their understanding. Instead, the research process ensured that, after the documents had been included with the managers' knowledge and perceptions, numerous opportunities were given for the managers to assess whether they felt their knowledge was being accurately presented.

\section{Understanding the nature and validity of the managers' implicit experiential knowledge}

\section{Nature and relevance of the knowledge}

The development of an individual's expert understanding of social-ecological systems is a complex and dynamic process (Fazey et al. 2005), and because each individual's expertise is built from a unique set of experiences, it can be difficult to compare the relative value of the knowledge of different experts (Baillie et al. 2001, 2002). Consequently, when using an expert's knowledge, it is important to clarify both the extent of the knowledge and its relevance to the issue being addressed (Fazey et al., in press).

The managers appeared to have extensive knowledge of the dynamic water flows and ecological responses in the wetland. This understanding had primarily been built by living in and around the wetland and responding in an adaptive way to ecological feedback. For example, the managers that grazed cattle on the wetland had responded flexibly for many years to the natural variation in flooding and consequent vegetation growth when feeding their cattle. Similarly, the Department of Environment and Conservation (DEC) reserve managers had learned by observing and reflecting on the wetlands' ecological responses to flooding to help them manage the reserve more effectively, e.g., observing the behavioral response of colonially-nesting waterbirds to flood events. Because such knowledge is primarily built by working with the natural dynamics and variation of ecological processes, it is highly relevant to understanding when the ecological system is undergoing significant change and the likely ecological causes of these changes. The knowledge of the managers will, therefore, have significantly greater relevance to understanding the degree to which the Marshes are threatened than will the knowledge of individuals and groups that do not live and work directly in and around the Marshes and/ or are involved in activities that aim to control and reduce ecological uncertainty and natural variability, e.g. agricultural enterprises that rely on irrigation.

The managers also exhibited a depth of understanding about the impediments to, and possible immediate options for achieving more effective water delivery. This understanding was based on their experiences in the development of water sharing plans, managing water allocated to maintaining ecological processes, and their interactions with institutions outside the immediate region of the Marshes. There will clearly be others in the Macquarie Valley with similar amounts of expertise who may have different opinions about the nature of the impediments and/or the best ways forward to take into account broader societal needs. Nevertheless, it is important to note that the managers were quite insistent about their claims of lack of neutrality by the water agencies, and presented evidence to back up their statements. The managers suggested that any lack of neutrality is likely to be because the agencies retain an overall implicit engineering and environmental controlling outlook derived from the original remit of the agencies to develop irrigation schemes (Fig. 5).

Although some of the managers had extensive knowledge about water delivery issues, their perceptions only reflect the opinions of a small group of people and, therefore, need validating. The water agencies whose legislative requirements direct them to serve a wide range of public interests, are likely to appear biased from the perspective of many different stakeholder groups who may be feeling that their interests are not being well served. However, the misgivings of the NSW government in the 1980s about the ability of the water agencies 
to serve different interests are highlighted in the DEP (1987) minutes provided by the managers. Further, the claims of the managers about the more recent behavior of the water agencies have been confirmed both by recent research into the history of managing the Marshes (Johnson 2005), and by recent, i.e., late 2005, actions by the NSW government that have recognized the problems and have transferred the responsibility for river restoration from the water agencies to the DEC.

The final aspect of the managers' knowledge was their perceptions of the reinforcing feedback between different social, economic, and ecological components of the broader system that made it difficult to achieve effective conservation. This understanding was built from the managers' general experiences of interactions with the wider community and institutions of the Macquarie Valley. The diagrams, therefore, only represent a small subset of a wide range of opinions, and there are likely to be many conflicting views of the issues presented. Nevertheless, this is the first formalized representation of the perceptions of any group about why it appears to be so difficult to conserve the Marshes. Therefore, these perceptions serve as a set of working hypotheses that can be tested using other sources of data. The conceptual model is also relatively simple, allowing other groups to begin to understand "where the managers are coming from." Such articulation and sharing of perspectives facilitates the development of common understanding within and between groups (e.g., Pahl-Wostl and Hare 2004) and is crucial for helping to resolve conflict (e.g., Lynam et al. 2002).

\section{Biases and validity of the knowledge}

Any individual or group of people will have certain biases that influence how they develop and articulate their experiential knowledge. This is because knowledge built from past experiences influences perceptions of future experiences and, thus, previous cultural, work, and personal experiences affect how people develop understanding. This is as true for researchers as it is for managers, because past experience guides research questions and how the results of research are perceived (Polanyi 1958, Fazey et al., in press).

The managers had certain biases. The underlying convictions of the managers demonstrate that they see a functioning Marshes ecosystem as essential for maintaining the local human community.
Furthermore, both the cattle graziers and the DEC reserve managers were directly dependent on a functioning wetland; the former for their livelihood and the latter for achieving successful work outcomes, i.e., the long-term conservation of the Marshes. Such personal interests are likely to have influenced certain aspects of their understanding such as those of the cattle graziers, which may have led them to put less emphasis on the ecological impacts of grazing (but see part 1, section 4 of the results).

Importantly, however, the perceptions of the managers also stem from their long-term and direct experience of ecological feedback, which is at least partly driven by their dependence on the wetland (see Whiteman and Cooper 2000). That is, the managers were more likely to develop ecological understanding because of the way in which they were dependent on the wetland, e.g., for cattle grazing, which meant that they were forced to work more closely with the wetland's natural dynamics. The participants of this study also expressed a strong identification and respect with the wetland and their immediate landscape in similar ways to descriptions of people who have a strong "sense of place" and of "being a place" (Livingston 1994). The triad of dependence, ecological feedback, and respect will have provided important personal intrinsic motivations for learning about the Marshes. Such learning is much more powerful and robust than learning that is influenced by carrot- and stick-type extrinsic factors such as government regulation and incentives (Deci and Ryan 1985, Ryan and Deci 2000).

The managers' experiences of observing and responding to the inherent variability of the ecological processes in the Marshes appear to have had three important influences. First, it is likely to have had strong influences on their understanding of the impediments to achieving effective water delivery. For example, their ecological understanding will have influenced how they perceive the degree to which a constriction in the river, caused by development on the floodplain, might affect water delivery to the Marshes. This would be quite different from the way it might be perceived by other people whose underlying assumptions to their knowledge are not primarily ecologically based.

Second, ecologically embedded understandings of the managers will also have affected how they developed their perceptions of why the conservation 
of the Marshes has generally been ineffective. For example, their understanding, gained through working flexibly with the uncertain and variable effects of flooding, is likely to have influenced their perceptions of the degree to which the actions of water agencies are dominated by attempts to control water flows. That is, the managers may be more likely to notice when attempts are made to reduce natural variability and the ecological impacts of such actions than people who place less importance on the need to maintain naturally variable water flows.

Finally, the embedded ecological basis to the managers' understanding means they are more likely to value the notion of adaptive management and work with, rather than try to control, natural processes. For example, one participant stated that it took at least $30 \mathrm{yr}$ of working within the system and observing the wetland's responses to flooding before they realised how complex the ecological system actually was. Another commented that they felt greater comfort when the ecological outcomes appeared uncertain, because they then knew that they were not making assumptions about the system's dynamics. That is, the managers naturally took an adaptive approach to management.

\section{Implications of the managers' understandings}

The discussion above highlights that although the managers' personal interests will clearly have influenced their understanding, their outlook and perceptions of the problems facing the Marshes is also largely based on their unique ecological understanding. These perceptions suggest that while immediate steps need to be taken to conserve the Marshes, long-term solutions are only likely to be achieved through a transformation of the current world views of the Macquarie Valley community to world views that favor more sustainable economic activity (Fig. 7). Societies often respond slowly to new problems, and appropriate regulation may come especially late if there are powerful stakeholder groups that benefit from maintaining the unregulated status quo (Scheffer et al. 2003). Thus, achieving such shifts in the perceptions of the wider community will not be easy.

The managers' perspectives of the problem also broadly highlight that ecological feedback is lacking in the Macquarie Valley social-ecological system (Fig. 7). This is a common issue in resource management (Chapin and Whiteman 1998,
Whiteman et al. 2004). Nevertheless, because the Marshes are located in the lower reaches of the Macquarie River, in which the effects of environmentally detrimental activities are most apparent, the Marshes have the potential to be promoted as a useful indicator of the overall health of the river system. If people who are directly or indirectly dependent on the Macquarie River, which includes the majority of those in the Macquarie Valley, can accept that the wetland provides a broad measure of the long-term ecological and economic sustainability of upstream human activity, there may be greater incentive to document and look more objectively at the causes of the ecological changes. That is, perceiving the health of the Marshes as an indicator may provide a social hook and the basis for a shared goal. Such a shared vision is essential if the trajectory of the system is to be transformed from one that may be heading toward ecological and social collapse to one that is heading toward maintaining social-ecological resilience (Olsson et al. 2004, Hahn et al., in press).

\section{CONCLUSIONS}

There are three main implications of the study about eliciting experiential knowledge. First, the paper supports the notion that people with considerable experience of receiving and responding to ecological feedback have valuable ecological knowledge that is relevant to environmental management. Second, developing such knowledge may engender greater recognition of the need to work adaptively within ecological systems. Third, the elicitation of implicit knowledge requires examination of not only the knowledge or information, per se, but also the underlying values and assumptions that go with it. Without such examination, the nature, relevance, and potential biases of the knowledge will be difficult to determine.

The managers' knowledge represents a particular perspective of a subset of people from the Macquarie Valley about the conservation of the Marshes. This perspective suggests that the Marshes are seriously threatened and that the main threat is lack of water. Although the extensive knowledge of the managers is likely to have been influenced by a range of personal experiences, it is also likely to be relatively unique in that it is derived from receiving 
and responding to ecological feedback within the wetlands. This means that the knowledge will be particularly useful for guiding future scientific research and management. Without such guidance, the effectiveness of scientific investigations and the management of the wetland will be seriously limited. All stakeholders clearly need to be involved in making decisions about whether it is worthwhile to conserve the Marshes and how the Macquarie Valley's water resources should be used. Nevertheless, such involvement should not be confused with the need for consulting people with the appropriate ecological expertise to help determine the degree to which the Marshes are threatened, the ecological causes of the threats, and the actions that are needed to restore and maintain the wetland's ecological processes.

Responses to this article can be read online at:

http://www.ecologyandsociety.org/voll1/iss 1/art25/responses/

\section{Acknowledgments:}

This work would not have been possible without the support and hospitality of the participants and the staff of the Coonabarabran Area office of DEC. We thank three anonymous reviewers for providing constructive comments, and D. Lindenmayer, $S$. Dovers, J. Fischer, and J. Clark who read earlier versions of the manuscript. Research funds were provided by the Centre for Resource and Environmental Studies and from D. Lindenmayer. IF was supported by an Endowment for Excellence Scholarship from The Australian National University.

\section{LITERATURE CITED}

Baillie, C., J. Emanuelsson, and F. Marton. 2001. Building knowledge about the interface in composite materials. Materials Research Innovations 3:365-370.

Baillie, C., J. Emanuelsson, and F. Marton. 2002. Building knowledge about the interface. Journal of Materials Education 22:77-83.

Barab, S.A., and J.A. Plucker. 2002. Smart people or smart contexts? Cognition, ability, and talent development in an age of situated approaches to knowing and learning. Educational Psychologist 37:165-182.

Berkes, F., J. Colding, and C. Folke. 2000. Rediscovery of traditional ecological knowledge as adaptive management. Ecological Applications 10:1251-1262.

Boiral, O. 2002. Tacit knowledge and environmental management. Long Range Planning 35:291-317.

Brander, D. 1987. Environmental changes in the Southern Macquarie Marshes 1934 to 1987. Thesis. School of Geography, University of New South Wales, Sydney, Australia.

Bransford, J. D., A. L. Brown, and R. R. Cocking. 2000. How people learn: brain, mind, experience, and school. National Academy Press, Washington, D.C., USA.

Brereton, G. J. 1994. An investigation into the impact of erosion in the southern Macquarie Marshes. Macquarie Marshes Management Strategy, Stage 1. Biophysical Investigations. Natural Resources Management Strategy Project. New South Wales Department of Water Resources, Dubbo, New South Wales, Australia.

Brereton, G. J., G. Steenbeeke, and T. Witts. 1996. A review of recent studies investigating the biological and physical processes in the Macquarie Marshes. Proceedings of the Macquarie Marshes Scientific Workshop (Dubbo, 1996). New South Wales Department of Land and Water Conservation, Dubbo, New South Wales, Australia.

Brereton, G. J., G. Steenbecke, and T. Witts. 2000. A review of recent studies investigating biological and physical processes in the Macquarie Marshes. New South Wales Department of Land and Water Conservation, New South Wales Government, Dubbo, New South Wales, Australia.

Brock, P. M. 1996. Landholder views on the boundaries of the Macquarie Marshes. Wetlands Australia. 15:62-81.

Brock, P. M. 1998. The significance of the physical environment of the Macquarie Marshes. Australian Geographer 29:71-90. 
Calheiros, D. F., A. F. Seidl, and C. J. A. Ferreira. 2000. Participatory research methods in environmental science: local and scientific knowledge of a limnological phenomenon in the Pantanal wetland of Brazil. Journal of Applied Ecology 37:684-696.

Chapin, F. S., and G. Whiteman. 1998. Sustainable development of the boreal forest: interaction of ecological, social, and business feedbacks. Ecology and Society 2:12.

Cotton Australia 2004. Australian Cotton History. Cotton Australia. Surry Hills, New South Wales, Australia.

Cunningham, G. 1996. Macquarie Marshes grazing study. Macquarie Marshes Management Committee.

Deci, E. L., and R. M. Ryan. 1985. Intrinsic motivation and self-determination in human behavior. Plenum Press, New York, New York, USA.

Department of Environment and Planning (DEP). 1987. Regional environmental plan for the Macquarie Marshes. Department's Minute. Page 9. Dubbo, New South Wales, Australia.

Macquarie and Cudgegong River Management Committee (MCRMC). 2002. Draft water sharing plan for the Macquarie and Cudgegong regulated rivers water source. Prepared by the Macquarie and Cudgegong River Management Committee for New South Wales Land and Water Conservation, Sydney, Australia.

Eslake, S. 2002. An introduction to the Australian economy. ANZ Bank. Sydney, Australia.

Fazey, I., J. A. Fazey, and D. M. A. Fazey. 2005. Learning more effectively from experience. Ecology and Society 10:2.

Fazey, I., J. A. Fazey, J. G. Salisbury, D. B. Lindenmayer, and S. Dovers. 2006. The nature and role of experience for environmental conservation. Environmental Conservation, in press.

New South Wales Government (NSW). 2000. An act to provide for the protection, conservation and ecologically sustainable development of the water sources of the state, and for other purposes. New South Wales Government 2000 Water Management
Act Number 92, Sydney, Australia.

Hahn, T., P. Olsson, C. Folke, and K. Johansson. 2006. Trust-building, knowledge generation, and organizational innovations: the role of a bridging organization for adaptive co-management of a wetland landscape around Kristianstad, Sweden. Human Ecology, in press.

Huntington, H. P. 2000. Using traditional ecological knowledge in science: methods and applications. Ecological Applications 10:1270-1274.

Johnson, W. 2005. Adaptive management of a complex social-ecological system: the regulated Macquarie River in south-eastern Australia. Thesis. University of New England, Armidale, Australia.

Jones, S. 2003. The Macquarie Marshes: a case study of conservation of wetlands by private landholders/managers. Wetlands Australia 11:20.

Kalu, O. U. 2001. The sacred egg: worldview, ecology, and development in West Africa. Pages 225-248 in J. A. Grim, editor. Indigenous traditions and ecology: the inter being of cosmology and community. Harvard University Press, Cambridge, UK.

Kidson, R., and G. Raisin. 2000. A review of recent studies investigating biological and physical processes in the MM: Proceedings of the Scientific Workshop, New South Wales Department of Land and Water Conservation. Dubbo, New South Wales, Australia.

Kidson, R., T. Witts, and W. Martin. 2000. Final project report: Macquarie Marshes management strategy stage 3: Implementation and audit Department of Land and Water Conservation, New South Wales Government, Dubbo, New South Wales, Australia.

Kingsford, R. T. 2004. Macquarie Marshes. in P. Olsen, and M. Weston, editors. The state of Australia's birds 2004. Report by Birds Australia: Courtney Colour Graphics, Dubbo, New South Wales, Australia.

Kingsford, R. T., and K. Auld. 2003. Waterbird breeding in the Macquarie Marshes. National Parks and Wildlife Service, New South Wales, Hurstville, Australia. 
Kingsford, R. T., and W. Johnson. 1998. Impact of water diversions on colonially-nesting waterbirds in the Macquarie Marshes of arid Australia. Colonial Waterbirds 21:159-170.

Kingsford, R. T., and R. F. Thomas. 1995. The Macquarie Marshes in arid Australia and their waterbirds: a 50 year history of their decline. Environmental Management 19:867-878.

Knight, S., and Partners. 1984. New South Wales Inland Rivers Flood Plain Management Studies. Report for the NSW Department of Water Resources, Sinclair, Knight and Partners, Sydney, Australia.

Kuhnert, P. M., T. G. Martin, K. Mengersen, and H. P. Possingham. 2005. Assessing the impacts of grazing levels on bird density in woodland habitat: a Bayesian approach using expert opinion. Environmetrics 16:717-747.

Lemly, A. D., R. T. Kingsford, and J. R. Thompson. 2000. Irrigated agriculture and wildlife conservation: conflict on a global scale. Environmental management 25 485-512.

Livingston, J. A. 1994. Rogue primate: an exploration of human domestication. Key Porter, Toronto, Ontario, Canada.

Lykke,A. M. 2000. Local perceptions of vegetation change and priorities for conservation of woodysavanna vegetation in Senegal. Journal of Environmental Management 59:107-120.

Lynam, T., F. Bousquet, C. Le Page, P. d'Aquino, O. Barreteau, F. Chinembiri, and B. Mombeshora. 2002. Adapting science to adaptive managers: spidergrams, belief models, and multiagent systems modeling. Conservation Ecology 5 (2):24.

Magrath, M. J. L. 1991. Waterbird breeding in the Macquarie Marshes 1989. Environmental Studies Unit, New South Wales Department of Water Resources, Dubbo, New South Wales, Australia.

Martin, T. G., P. M. Kuhnert, K. Mengersen, and H. P. Possingham. 2005. The power of expert opinion in ecological models: a Bayesian approach to examining the impact of cattle grazing on birds. Ecological Applications 10:266-280.
Masman, K., and M. Johnstone. 2000. Reedbed country: the story of the Macquarie Marshes. Macquarie Marshes Management Committee. Tamworth, New South Wales, Australia.

Millenium Ecosystem Assessment. 2005 Ecosystems and human well-being: synthesis. Island Press, Washington, D.C., USA.

National Parks and Wildlife Service (NPWS). 1993. Macquarie Marshes Nature Reserve plan of management. Prepared by the Coonabarabran District Office, New South Wales National Parks and Wildlife Service, Dubbo, New South Wales, Australia.

New South Wales Government (NSW). 2000. Water Management Act, Chapter 2, Part 1, Division 1. NSW, Dubbo, New South Wales, Australia.

O'Connell, M. J. 2003. Detecting, measuring, and reversing changes to wetlands. Wetlands Ecology and Management 11:397-401.

Olsson, P., and C. Folke. 2001. Local ecological knowledge and institutional dynamics for ecosystem management: a study of Lake Racken Watershed, Sweden. Ecosystems 4:85-104.

Olsson, P., C. Folke, and F. Berkes. 2004. Adaptive comanagement for building resilience in socialecological systems. Environmental Management 34:75-90.

Pahl-Wostl, C., and M. Hare. 2004. Processes of social learning in integrated resources management. Journal of Applied and Community Psychology 14:193-206.

Pierotti, R., and D. Wildcat. 2000. Traditional ecological knowledge: the third alternative. Ecological Applications 10:1333-1340.

Polanyi, M. 1958. Personal knowledge: towards a post-critical philosophy. Routledge Kegan Paul, London, UK.

Proust, K. 2004. Learning from the past for sustainability: towards an integrated approach. Dissertation. Centre for Resource and Environmental Studies, Australian National University, Canberra, Australia.

Richter, B. D., J. V. Baumgartner, J. Powell, and 
D. P. Braun. 1996. A method for assessing hydrologic alteration within ecosystems. Conservation Biology 10:1163-1174.

Robertson, H. A., and T. K. McGee. 2003. Applying local knowledge: the contribution of oral history to wetland rehabilitation at Kanyapella Basin, Australia. Journal of Environmental Management 69:275-287.

Ryan, R. M., and E. L. Deci. 2000. Selfdetermination theory and the facilitation of intrinsic motivation, social development, and well-being. American Psychologist 55:68-78.

Scheffer, M., F. Westley, and W. Brock. 2003. Slow response of societies to new problems: causes and costs. Ecosystems 6:493-502.

Smith, D. I. 1998. Water in Australia: resources and management. Oxford University Press, Melbourne, Australia.

Sterman, J. D. 2000. Business dynamics-systems thinking and modeling for a complex world. McGraw-Hill, Boston, Massachusetts, USA.

Sutherland, W. J.,A. S. Pullin, P. M. Dolman, and T. M. Knight. 2004. The need for evidence-based conservation. Trends in Ecology and Evolution 19:305-308.

Vennix, J. A. M. 1996. Group model building: facilitating team learning using system dynamics. Wiley, Chichester, UK.

Whiteman, G., and W. H. Cooper. 2000. Ecological embeddedness. Academy of Management Journal 43:1265-1282.

Whiteman, G., B. C. Forbes, J. Niemela, and F. S. Chapin. 2004. Bringing feedback and resilience of high-latitude ecosystems into the corporate boardroom. Ambio 33:371-376.

Wolfgang, C. A. 2000. Hydrogeology of the Pilliga sandstone aquifer in the Western Coonamble embayment and its implications for water resource management. Centre for Resource and Environmental Studies. Australian National University, Canberra, Australia.

Woodlots and Wetlands Ltd. 2004. Macquarie Marsh River Red Gum survey. Prepared for the
Department of Environment and Conservation, Castle Hill, Australia.

Woodwell, G. M. 1989. On causes of biotic impoverishment. Ecology 70:14-15. 


\section{APPENDIX 1. The Research Process - the 'Marshes Approach'}

The Marshes Approach consisted of seven stages, many of which provided opportunities for the primary researcher to reflect on the results, and to seek clarification from the participants about the accuracy of the interpretation of their implicit understanding. Importantly, during the 6 month period of data collection, the primary researcher was predominantly based in the Coonabarabran Area Office of DEC.

In stage one (6 weeks) the first author participated in day-to-day management activities of the Marshes, working as a volunteer of DEC. This allowed familiarisation with the study area and its issues, and gave time to identify potential participants for the study and to gain their trust.

In stage two, each manager was interviewed twice. During the interviews, managers were asked to describe the "Marshes system". They were encouraged to draw a boundary around the parts of the system that they felt were most relevant to the conservation of the Marshes. In all cases, the managers took a broad system view. They did not consider the ecological components of the Marshes in isolation to the physical, social, political and economic components.

In both interviews, the interviewer (first author) used open-ended questions to begin construction of a conceptual model to describe the Marshes system. As the interviewee talked, the researcher built up a rough structural diagram of the topic that was being discussed, with preliminary causal links between different variables (i.e. a detailed spidergram). This enabled an initial exploration of some of the complex feedback effects that were occurring in the Marshes socio-biophysical system (similar to the approach used in Vennix 1996).

At the beginning of the first interview, the participants were invited to discuss what they considered to be the most important issues and aspects of the Marshes system. In the second round of interviews (1-3 weeks after the first round), the managers were shown data generated from the first interview, and a list of all topics discussed by the participants. They were then asked to elaborate on one of the topics, or discuss another topic, which had not yet been considered. By the end of the second interview, the raw data consisted of two sets of detailed spidergrams per individual (except in one case where two participants had been interviewed together at the same time as their second interview). As the overall intention was to capture the understanding of the managers, discussions up to this point had not been led in any particular direction, and no assumptions by the researcher had been made about what constituted the most important or relevant issues affecting the Marshes.

The third stage centred around a workshop (20 $0^{\text {th }}$ July 2004) with the aim of gaining deeper insights into the operation of the Marshes system. An attempt was made to identify changes which had affected the conservation or management of the Marshes in both positive and negative ways. At the beginning of the workshop, four underlying convictions from which the workshop could progress were presented (see results). These convictions were based on information already derived from interviews, and managers were asked if they agreed with them before the workshop commenced. The workshop was facilitated by B. Newell and separate notes were taken by both I. Fazey and K. Proust to ensure that the discussion was adequately captured, and to reduce any bias in its interpretation.

In stage four, a preliminary conceptual model was built which integrated components of the data from individual interviews and from the workshop. The model was built by the primary researcher and provided the basis for stage five where, in a third round of individual interviews, the managers were asked to comment on the initial conceptual model, clarify issues discussed in earlier stages, and remove or add information that was either lacking in emphasis or was considered to be unimportant.

In stage six, all information was distilled and integrated to produce a set of tentative hypotheses (CLDs) that explain why there appears to be so little positive conservation action in favour of the Marshes. This was based primarily on the preliminary conceptual model, the researchers' understanding of the 
participants' perceptions and the feedback from individual managers in stage four. In stage seven, the sections of the results (including the CLDs) were discussed at a final meeting with all participants to ensure that their implicit knowledge had been articulated accurately. This included the language used and relative emphasis of different aspects of the managers' knowledge and perceptions. 
APPENDIX 2. Historical basis of current pressures on water resources (as perceived by the managers)

In Australia, historically, irrigation has been strongly supported through subsidies, price-maintenance schemes, tariff barriers and cheap water. Governments have invested heavily in infrastructure, with a tenfold increase in the capacity of major dams between 1940 and 1990 (Smith 1998). In the Macquarie Valley, the first weirs and their off-takes were constructed in 1896 to improve water supply for pastoral purposes. As the extent of water control structures increased, so did the potential for irrigation. Plans for the construction of Burrendong Dam were made in 1907 and 1934, but were consistently and heavily opposed by settlers on the Lower Macquarie River, who argued that the extraction of so much water would prejudice their established interests (S. Knight and Partners, 1984). By the early 1940s, a large number of river regulation structures and water off-takes had been constructed, and there was greater pressure on water agencies and the government to service an irrigation industry. Burrendong dam was authorised in 1946, and completed in 1966. The increased stability of river flows enabled the growth of cotton which was first planted in the valley within one year of the completion of the dam (Cotton Australia, 2004). The irrigation industry expanded rapidly from 17,500 ha in $1965-1969$ to 85,577 ha in 1990 (Kingsford and Thomas 1995).

The CLD in Appendix 3 illustrates some aspects of irrigation development. An increasing number of people engaged in irrigation led to greater demand for the control of water resources so as to reduce the risk associated with variable river flows. This led to increased pressure on government to service the irrigation industry, raising the potential for irrigation and increasing the number of people involved in such activities.

Four other significant factors contributed to current pressure on water resources. First, the amount of water in the river was significantly over-allocated. In the early 1970s water licences were issued to attempt to regulate water extraction. However, two unusually large floods in the 1950's influenced estimates of the amounts of water available in the catchment and the dam was re-designed to hold three times the amount originally intended (Knight and Partners, 1984). Licences were also granted even when it was apparent that demand would exceed supply, and many landholders in the Central Macquarie Valley began to subdivide their properties to obtain multiple licences (Masman and Johnstone 2000).

Second, in the late 1980s and early 1990s, changes in licence regulations enabled licence holders to sell the water allocated to them, rather than have the water licence tied to a particular piece of land. This allowed licence holders to sell water if they were not intending to use it themselves, increasing the likelihood of over-use (Crase et al. 2004).

Third, greater predictability through regulation of the water supply has resulted in increased expectation that water will generally be attainable. For example, irrigators may plant cotton at the beginning of a season without knowing whether or not water will be available to finish the crop. Later in the season they have argued that they will suffer economic loss without additional allocation of water. In some cases, it is believed that water that was supposed to have been kept as part of the allocation to other stakeholders has been given to service the needs of irrigation, despite objections from those other stakeholders (e.g. use of town water in October 2003).

Fourth, pressure on water resources is greatest during periods of low water availability, such as the 2001- current (2005) drought, resulting in significant conflict between water user groups (see Figure 4). 
APPENDIX 3. Irrigation Development in New South Wales. The reinforcing causal loop (R) illustrates some of the historical factors in irrigation development. When contemporary factors are taken into account, the combined effects increase the demand on water resources in the catchment. Note the delays. See text for details.

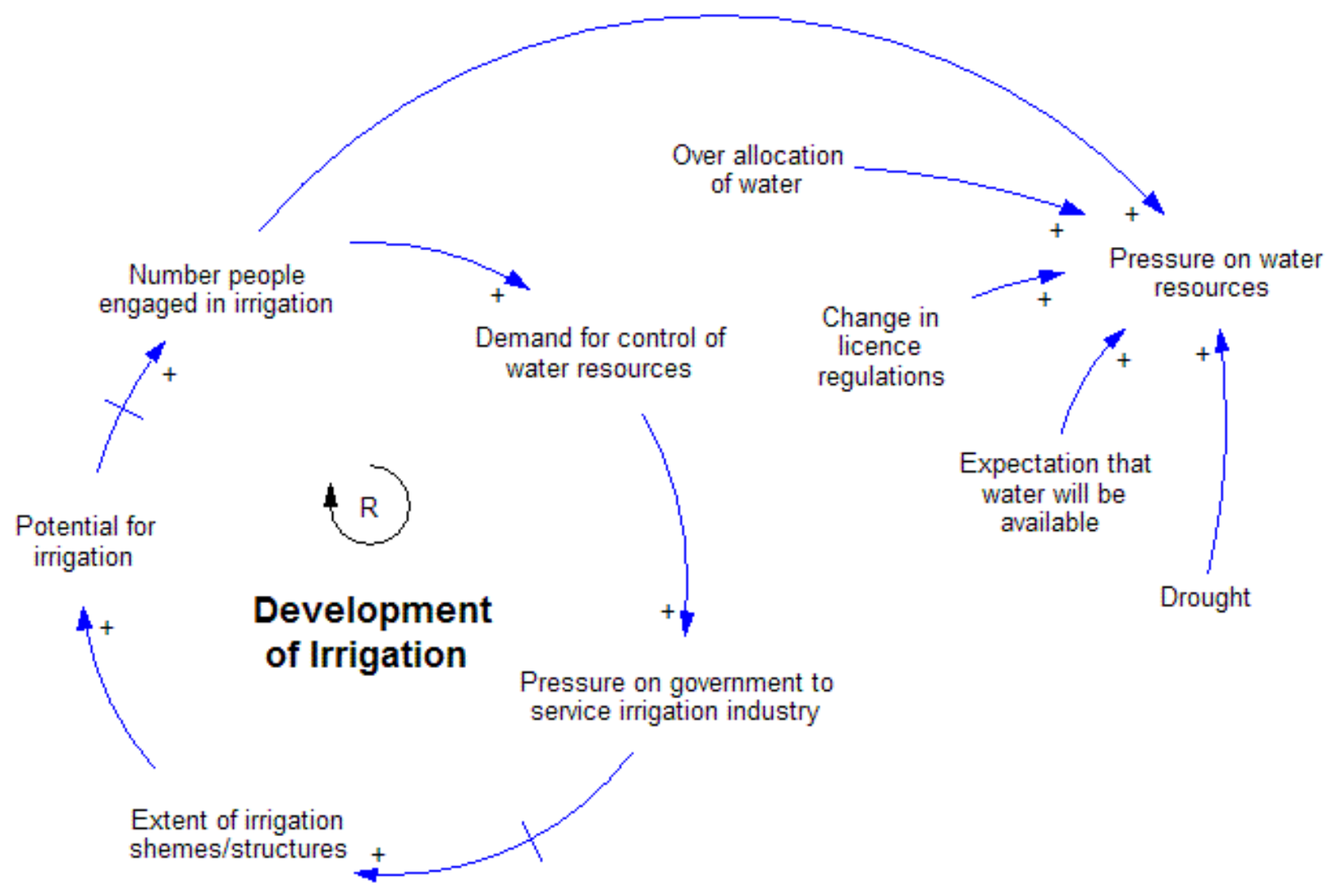

